\title{
Spectral recording of gene expression history by fluorescent timer protein
}

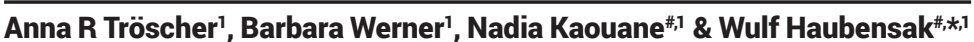

\begin{abstract}
Monitoring spatiotemporal patterns of gene expression by fluorescent proteins requires longitudinal observation, which is often difficult to implement. Here, we fuse a fluorescent timer (FT) protein with an immediate early gene (IEG) promoter to track live gene expression in single cells. This results in a stimulusand time-dependent spectral shift from blue to red for subsequent monitoring with fluorescence activated cell sorting (FACS) and live cell imaging. This spectral shift enables imputing the time point of activity post-hoc to dissociate early and late responders from a single snapshot in time. Thus, we provide a tool for tracking stimulus-driven IEG expression and demonstrate proof of concept exploiting promoter::FT fusions, adding new dimensions to experiments that require reconstructing spatio-temporal patterns of gene expression in cells, tissues or living organisms.
\end{abstract}

\section{METHOD SUMMARY}

Our approach enables spatio-temporal resolution of gene expression in single cells and "saving" the gene expression history of a cell by a fluorescent timer expressed under an immediate early gene promoter. The constant kinetics of the spectral shift enabled the post-hoc identification of cellular activation from a single snapshot in time.

\section{KEYWORDS}

flow cytometry fluorescent timer protein $\cdot$ gene expression $\cdot$ immediate early genes • live cell imaging $\cdot$ spatiotemporal resolution

${ }^{1}$ Research Institute of Molecular Pathology (IMP), Vienna Biocenter (VBC), Campus Vienna Biocenter 1, 1030 Vienna, Austria; ${ }^{\ddagger}$ Authors contributed equally; *Author for correspondence: wulf.haubensak@imp.ac.at

BioTechniques 67: 154-164 (October 2019) 10.2144/btn-2019-0050

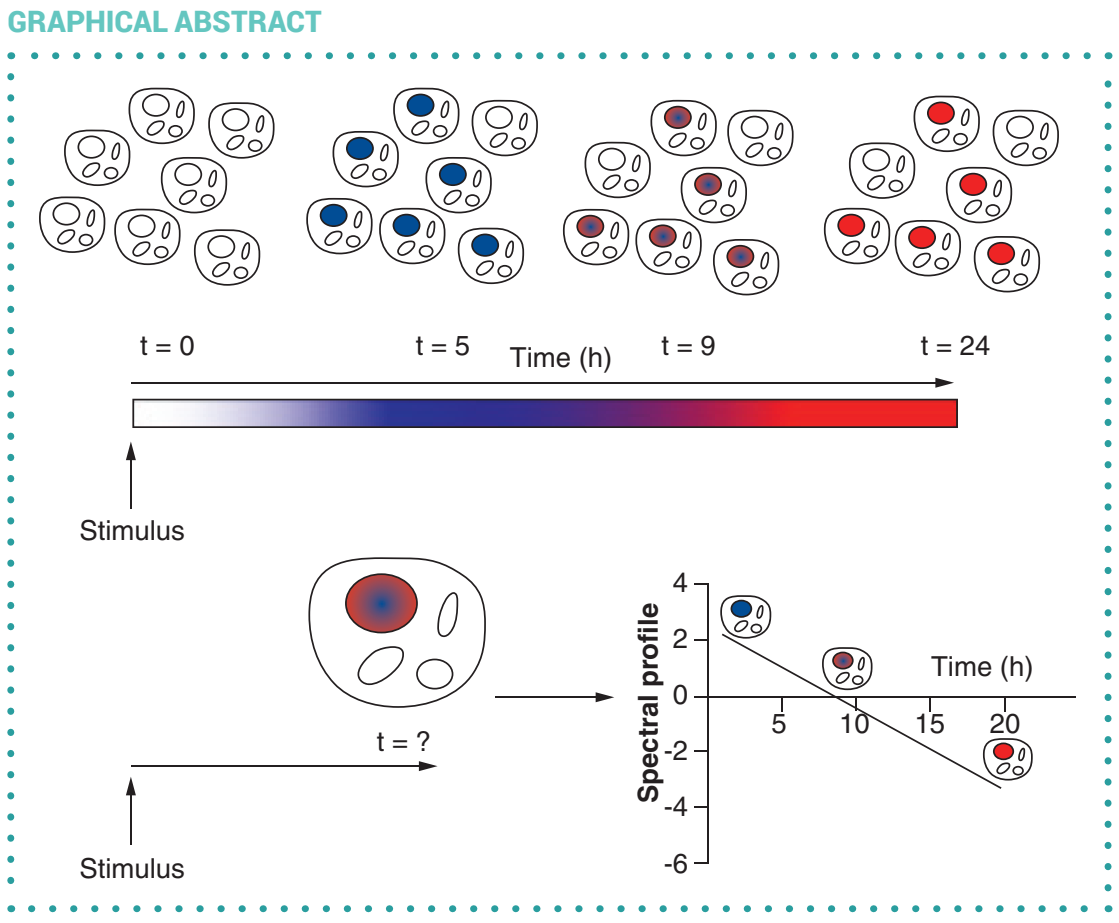

Multiple methodologies across biology must monitor gene expression dynamics in cell populations, such as determining gene expression profiles over time. Typical approaches use live reporters expressed under the control of the respective gene (either as a promoter or coding sequence fusion). One widely used reporter, GFP [1], can serve as a fluorescent protein (FP) fusion tag [2,3]. Combining FP technology with dynamic imaging, 'photo-activation', 'photo-bleaching' or photo-switchable proteins [4-8] permits straightforward longitudinal tracking of cellular genetic activity. However, these monitoring strategies suffer from an inherent drawback that requires samples to be accessible for imaging and/or manipulation over extended durations.

An equally prominent set of applications aims to compare cell types with different gene expression histories from heterogeneous populations, such as genetic screens in cell culture or reconstructing neuronal activity maps in the brain. To date, this requires reconstructing cellular gene expression history from a laborious and expensive assembly of individual chronologically ordered time series.

Thus, a significant need exists for an efficient means to differentiate where and when a gene is active in a single cell from a heterogeneous, complex cell population that does not rely on continual imaging or a post-hoc reconstructed time series. We predict the fast-maturing FT protein using mCherry, which changes color from blue to red over time [9] and provides the necessary temporal information when a gene is expressed. In contrast to tetramer FT proteins [10-12], the FT used here is a monomer and can serve as a protein fusion tag [9]. By fusing this tool with a gene of interest, such promoter::FT fusions will reveal the expression 'history' of that gene in a cellular population. As proof of concept, we chose to monitor IEG expression. IEGs often serve as a proxy for cellular activation upon external 


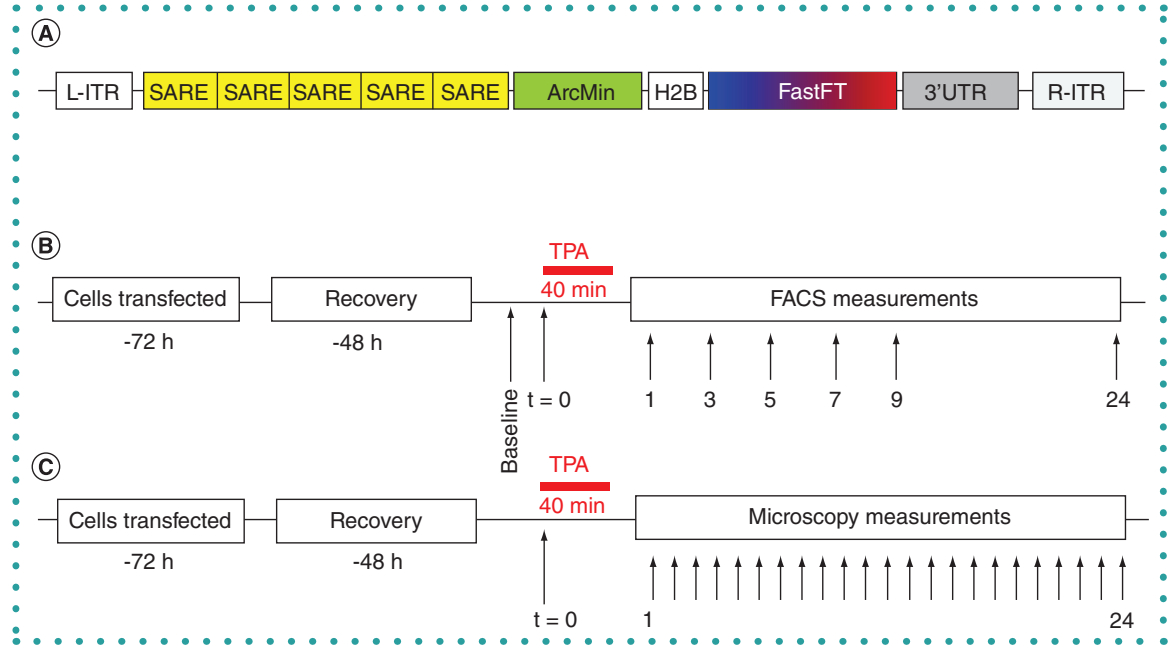

Figure 1. Design of expression vector and experiment. (A) Graphic scheme of the constructed plasmid including the E-SARE + ArcMin promoter and the fast FT coding sequence. (B) Overview of experimental procedure for FACS measurements. (C) Overview of experimental procedure for live cell imaging.

FT: Fluorescent timer; ITR: Inverted terminal repeat; TPA: Phorbol 12-myristate 13-acetate.

- growth factor or neuronal stimulation in complex tissues.

Here, we inserted the FT sequence under an IEG promoter. To overcome the previously reported low brightness of FT $[5,13]$, we exploited the enhanced synaptic activityresponsive element (E-SARE). Kawashima et al. demonstrated that multiplexing of SARE (which they termed E-SARE) linked to the proximal Arc promoter (ArcMin) significantly elevated the FP fluorescent signal under this promoter compared with other IEG promoters [14]. By combining these approaches, we created a tool to dissect activity-dependent gene expression with spatio-temporal resolution.

\section{MATERIALS \& METHODS}

Fluorescent timer protein construct

To implement spatio-temporal tracking of cellular activity, we expressed the FT, an mCherry variant, which changes its color from blue to red over time [9] under control of an IEG promoter. To achieve this and overcome reported low brightness $[5,13]$ of FT under endogenous promotors, we exploited the previously reported expression cassette consisting of synthetic combination of an ArcMin promoter (part of the IEG Arc/Arg-3.1 transcription initiation site in the mouse genome), with the E-SARE (5× SARE enhancer fragment Arc/Arg-3.1 transcription initiation site in the mouse genome) complex and the 3'-UTR region c-Fos mRNA to mimic endogenous stability of IEG RNA turnover [14]. For our spectral recording construct, we swapped the GFP [14] for FT (31913, Addgene). As the FT signal was found to be weak and difficult to allocate to one cell in a pilot study (data not shown), we equipped the construct with the histone 2B nuclear localization signal for easier quantification and registration of the fluorescent signal. The whole sequence was then inserted into the adeno-associated virus (AAV) plasmid between the two inverted terminal repeats (Figure 1A). All sequences were obtained from Invitrogen.

\section{Cloning of the plasmid}

Two restriction digests were performed with Notl (\#FD0594, Fermentas) at $37^{\circ} \mathrm{C}$ for $2 \mathrm{~h}$. One linearized the vector, while the other cut out the insert (E-SARE/ArcMinH2B-fosUTR). The vector was subsequently dephosphorylated with alkaline phosphatase (10713023001, Roche Diagnostics) to prevent self-ligation of the vector for $30 \mathrm{~min}$ at $37^{\circ} \mathrm{C}$. The sample was then loaded on a $1 \%$ agarose gel, the bands were cut and a gel extraction performed (\#28706, QIAquick Gel Extraction Kit, Qiagen) according to the manufacturer's instructions. The ligation of the vector with the insert containing the E-SARE-ArcMin promoter and $\mathrm{H} 2 \mathrm{~B}$ was performed using a T4 ligase (\#EC0011, Thermo Scientific) overnight at $16^{\circ} \mathrm{C}$.

Then, a heat shock transformation was performed, and bacteria incubated on
$\mathrm{LB}+$ Ampicilin plates at $37^{\circ} \mathrm{C}$ overnight. Colonies were picked and again incubated overnight at $37^{\circ} \mathrm{C}$ in $5 \mathrm{ml} \mathrm{LB}+$ Ampicilin $(100 \mu \mathrm{g} / \mathrm{ml})$. Consecutively, a plasmid miniprep was performed (plasmid miniprep Kit, Qiagen, \#12123) according to the kit protocol. The DNA concentration was determined using a nanodrop (Nanodrop 2000c, Thermo Scientific). Following another transformation and overnight incubation in $2 \mathrm{ml}$ LB + Ampicilin, 1 I medium was added and incubated overnight at $37^{\circ} \mathrm{C}$ for a plasmid maxiprep (Plasmid maxi kit, Qiagen, 12162), which was performed according to the kit protocol. In a final step, the plasmid was sequenced by the in-house sequence facility of IMP/IMBA.

\section{Cell culture}

HeLa (ATCC, CCL2) cells were incubated overnight at standard incubator conditions (at $37^{\circ} \mathrm{C}, 5 \% \mathrm{CO}_{2}$ ) on a 6 -well plate in DMEM $+10 \%$ fetal calf serum (Life Technologies), 1\% penicillin/streptomycin (Pen/ Strep; Life Technologies) and 1\% L-Glutamine (Life Technologies) to achieve a confluency recommended in the manual of the transfection reagent.

\section{Transfection}

Transfection was performed with the TransIT-LT1 transfection reagent (MIR2304, Mirus Bio LLC) according to the manufacturer's instructions. In short, cells were grown to a confluency of about $80 \%$. The Opti-MEM I reduced-serum medium was mixed with the plasmid in a concentration of $1 \mu \mathrm{g} / \mu \mathrm{l}$. Then, TransIT-LT1 reagent was added and incubated for $30 \mathrm{~min}$ at room temperature. The mixture was then added to the cell culture and incubated for $24 \mathrm{~h}$.

Fluorescence activated cell sorting (FACS) For an exact determination and quantification of the kinetics of the color change, a FACS (BD LSR Fortessa2, BD Biosciences) was performed (Figure 1B). To this end, HeLa cells were transfected as described above. To decrease the risk of any preliminary expression of the FT protein due to the medium change, cells were left for $48 \mathrm{~h}$ in the incubator without disturbance. Then half of the cells were treated with $100 \mathrm{ng} / \mathrm{ml}$ phorbol 12-myristate 13-acetate (TPA; P8139, SigmaAldrich), which was diluted in the culture medium (with $t=0$ corresponding to the 
moment TPA was added). The control cells without FT induction (-TPA) received the same cell culture medium, but without TPA. After $40 \mathrm{~min}$, the medium was removed from all wells, including those not treated with TPA; cells were washed with PBS and fresh medium added. For each measurement, cells from one well were dislodged using trypsin/ EDTA (Life Technologies) directly before each measurement, including mitotic cells. The first measurement was performed $1 \mathrm{~h}$ after the start of the TPA treatment. The fluorescent measurement was repeated every $2 \mathrm{~h}$ for $9 \mathrm{~h}$. The next measurement was performed at $24 \mathrm{~h}$. Measurements were done for blue isoform with $405 \mathrm{~nm}$ violet laser, coherent cube (403-408) $100 \mathrm{~mW}$, detection at $450 \mathrm{~nm}$ and for the red isoform with $561 \mathrm{~nm}$ yellow green laser, coherent sapphire $100 \mathrm{~mW}$, detection at $670 \mathrm{~nm}$. Analysis was done with FlowJo V10 software (FlowJo, LLC) and data represent three independently performed experiments. of fluorescent change over time of single cells $(n=10)$, ImagePro Premier (Media Cybernetics, version 9.3) was used. For quantification of the cell number positive for either blue or red fluorescence, images from three different areas were analyzed, and cells with a nuclear fluorescent signal counted manually. For determining the cellular fluorescent intensity, nuclei were detected in a semi-automated manner with the cell quantification tool from the software ImagePro Premier. Fluorescence was measured within the nucleus of each cell if it exceeded a manually set threshold. Percentage of cells positive for each color was calculated to the maximum number of cells positive for each color.

To differentiate cells into early and late responders, cells were split into two groups, depending on the time needed to reach the blue fluorescent maximum. Cells responding before the median were grouped as early responders, whereas cells that required more or equal time than the median were allocated to the late responder group.

\section{Mathematical extrapolation}

of cellullar activity

For the mathematical differentiation of induced and noninduced cells, z-scores of the fluorescent intensity for each color were calculated from a total of 20 cells. The mean and SD for both colors were calculated separately, including all cells and timepoints of interest. Z-scores were then calculated by subtracting the value of interest by the mean and dividing through the SD of the respective color. To determine the time point of cellular activity of individual cells during the live cell imaging, we established a mathematical model that allows extrapolating gene activity depending on the ratio of blue to red fluorescence. Thus, the change of the fluorescent signal of blue and red over time was calculated. To this end, the logarithm of the ratio of the fluorescent

\section{Microscopy}

Cells were transferred into chambered cell culture slides (8-well Cell Culture Slides, CCS-8 MatTek Corporation) and grown overnight. ArcMin expression was induced by adding $100 \mathrm{ng} /$ $\mathrm{ml}$ TPA, which was diluted in culture medium. Cells without TPA induction (-TPA) received culture medium without TPA. After $40 \mathrm{~min}$, the medium was changed in all wells (also in wells not treated with TPA) to stop the induction. Cells were imaged for $24 \mathrm{~h}$ using a spinning disk microscope (Spinning Disk Confocal UltraView Vox controlled by the software Volocity, Objective: 20×/0.3 EC plan Neofluar Ph1 DICl) and pictures of every dish were taken every hour at three different locations (Figure 1C). For the blue isoform, measurements were performed with $405 \mathrm{~nm}$ excitation and 410-460 $\mathrm{nm}$ emission. For the red isoform, they were performed with $561 \mathrm{~nm}$ excitation, 570-630 nm emission. For the quantification

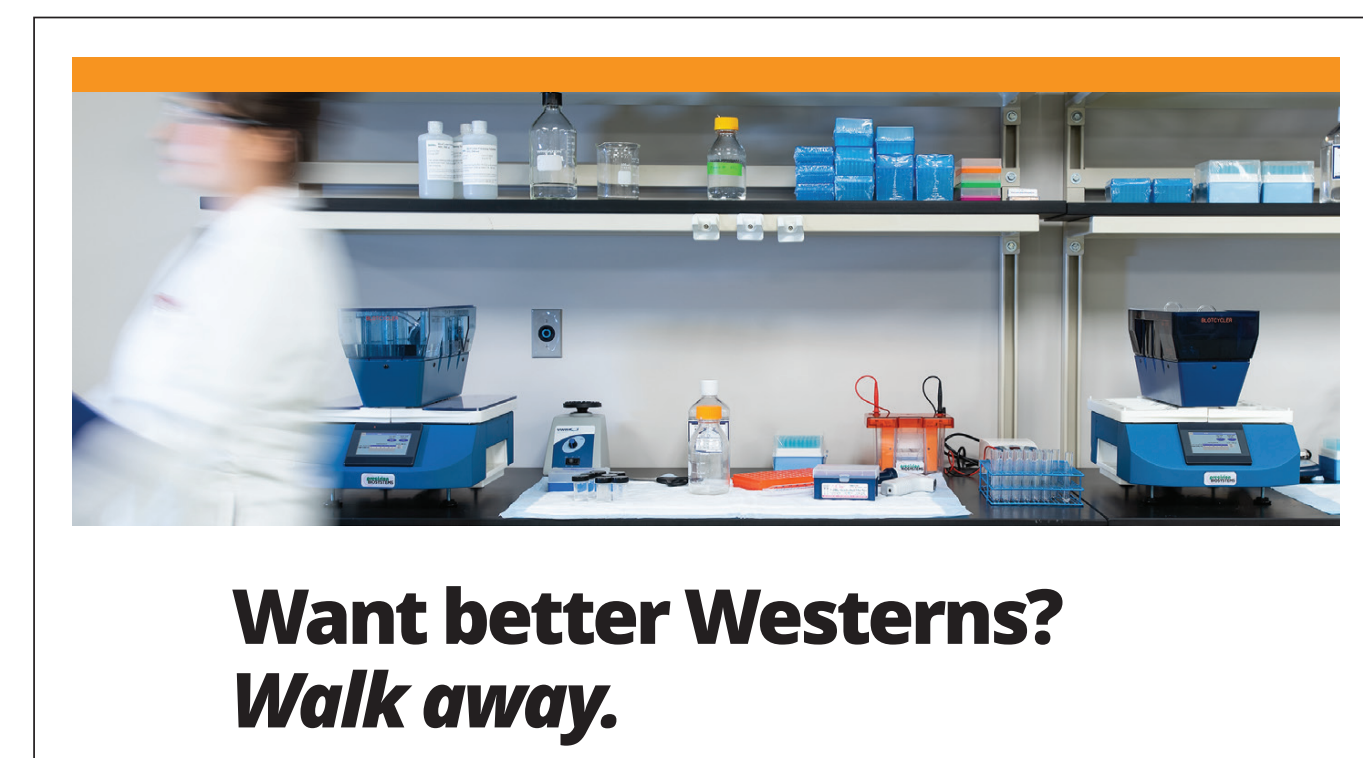

Traditional western blot analysis is a time-consuming process. BlotCycler $^{\text {TM }}$ changes everything by automating the fluid changes and timing associated with blocking, washing and antibody

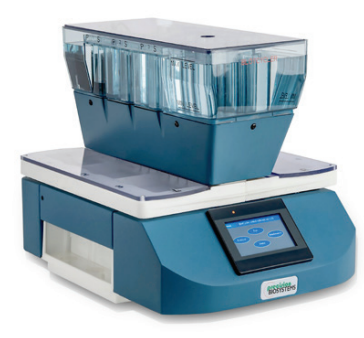
incubation. There's no more need to watch over the procedure. With BlotCycler, simply set up your protocol, and walk away!

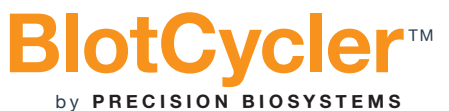

www.blotcycler.com 


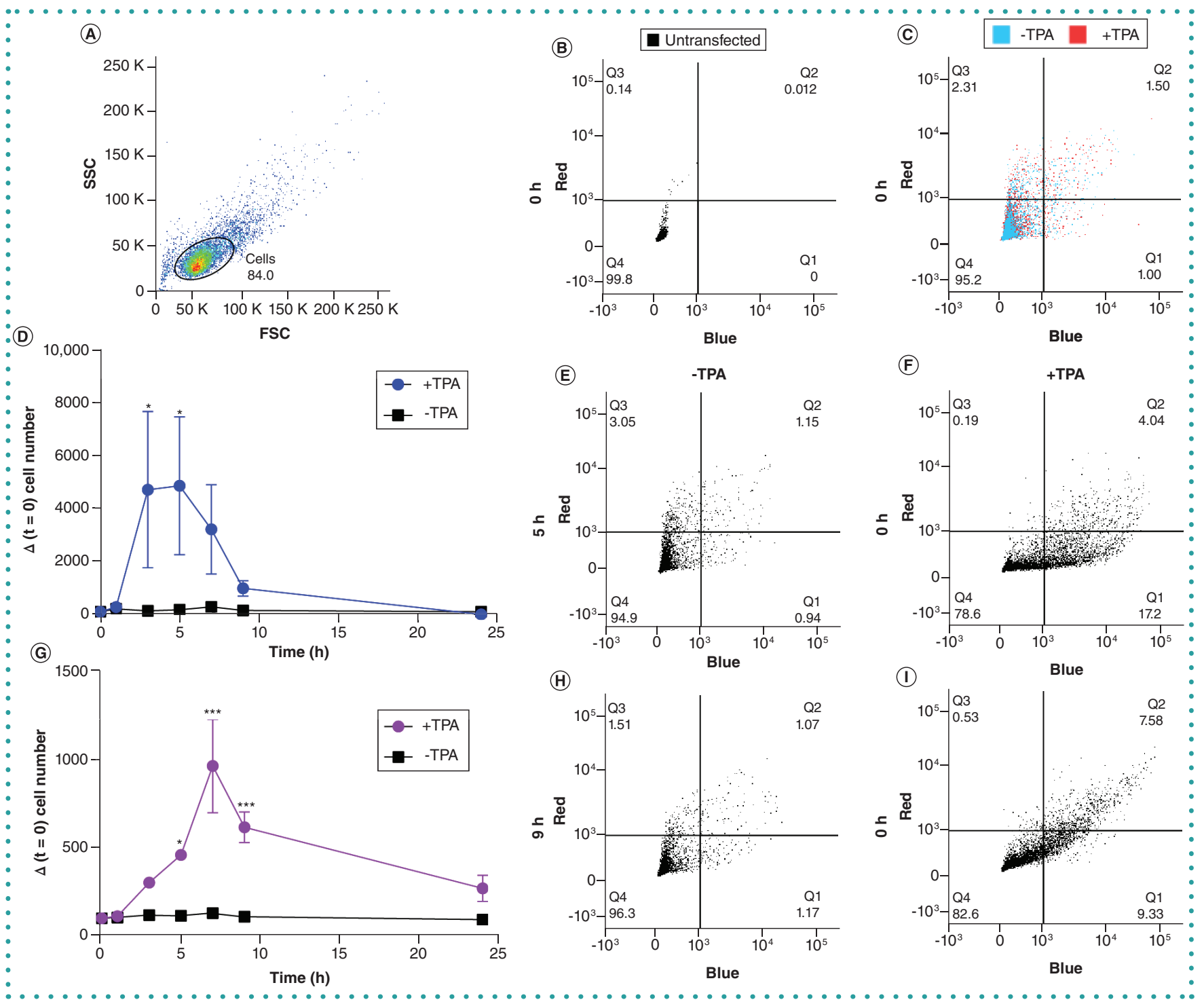

Figure 2. Phorbol 12-myristate 13-acetate-induced fluorescent timer expression and a time-dependent spectral shift. (A) The general gating strategy for fluorescence activated cell sorting (FACS) sorting of viable cells is indicated by the solid-line circle. (B) Untransfected cells stimulated with TPA showed only very sparse autofluorescence with most cells not showing any signal, indicated by the fraction of cells shown in the respective quadrant (Q1-4). (C) Both groups (with and without TPA stimulation) did show only rare blue/red fluorescence at the baseline measurement $(t=0)$. (D) Activated cells $(+T P A)$ showed a significant increase of relative cell number compared with baseline $(t=0)$ positive for blue fluorescence at 3 and $5 \mathrm{~h}$ post-induction compared with transfected cells without TPA induction (-TPA). Representative FACS sorting images of cells (E) without TPA and (F) with TPA stimulation $5 \mathrm{~h}$ postinduction. (G) The number of cells positive for both blue and red fluorescence significantly increased 7 and $9 \mathrm{~h}$ post-induction in the activated group (+TPA) compared with the unstimulated group (-TPA). Representative FACS sorting images of cells (H) without TPA and (I) with TPA stimulation $9 \mathrm{~h}$ post-induction. $* \mathrm{p}<0.05 ; * * \mathrm{p}<0.01 ; * * * \mathrm{p}<0.001$.

FU: Fluorescence units; FSC: Forward scatter; SSC: Side scatter; TPA: Phorbol 12-myristate 13-acetate.

$\checkmark$ intensities of five randomly chosen cells was plotted over time. In a next step, the linear curve function was used to extrapolate the time point of cellular activity of five cells (again randomly chosen) from the same experiment with unknown induction time points. To verify this approach, we repeated these calculations with a larger dataset with a total of 18 randomly chosen cells from an independent experiment. For the mathematical differentiation of early and late responders, the median response rate to the stimulus was used as a cut-off. If the calculated response was before the median, cells were grouped as early responders, whereas cells, for which the calculated response time was more or equal than the median, were allocated to the late responder group.

$$
y=\log 10\left(\frac{\text { blue }_{n}-\text { blue }_{t 1}}{\text { red }_{n}-r e d_{t 1}}\right)
$$

\section{Statistical analysis}

Data are presented as mean \pm SEM. Statistical analyses were performed using GraphPad PRISM (GraphPad Software, Inc.). Two-way ANOVA was performed to determine color change over time, as well as the difference between early and late responders with repeated measurement for microscopy analysis. $p \leq 0.05$ was considered statistically significant. For the calculation of the linear curve function, a linear 

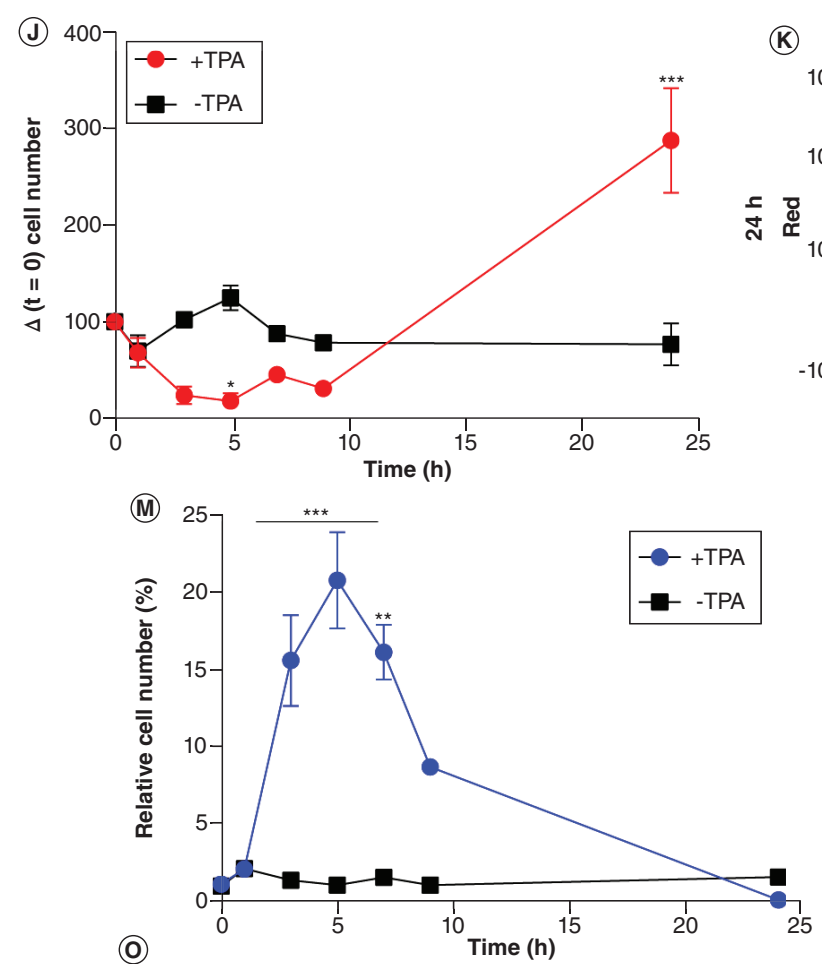

(2)

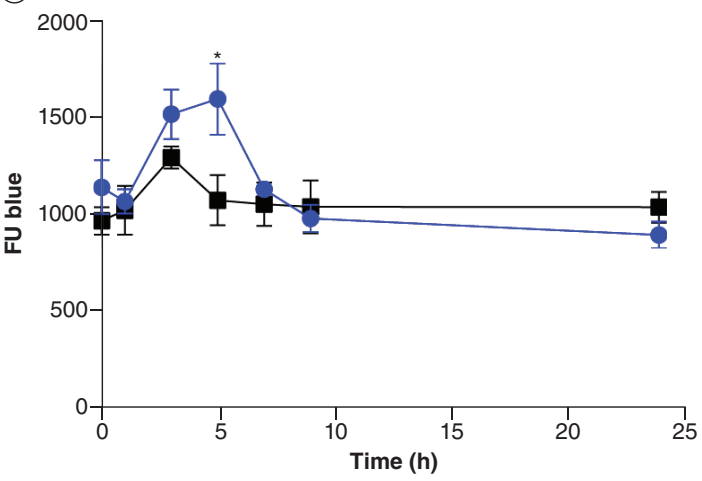

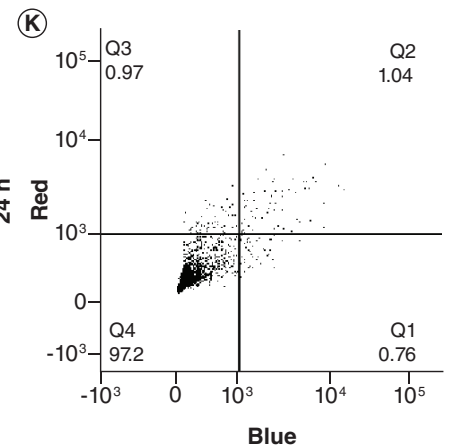
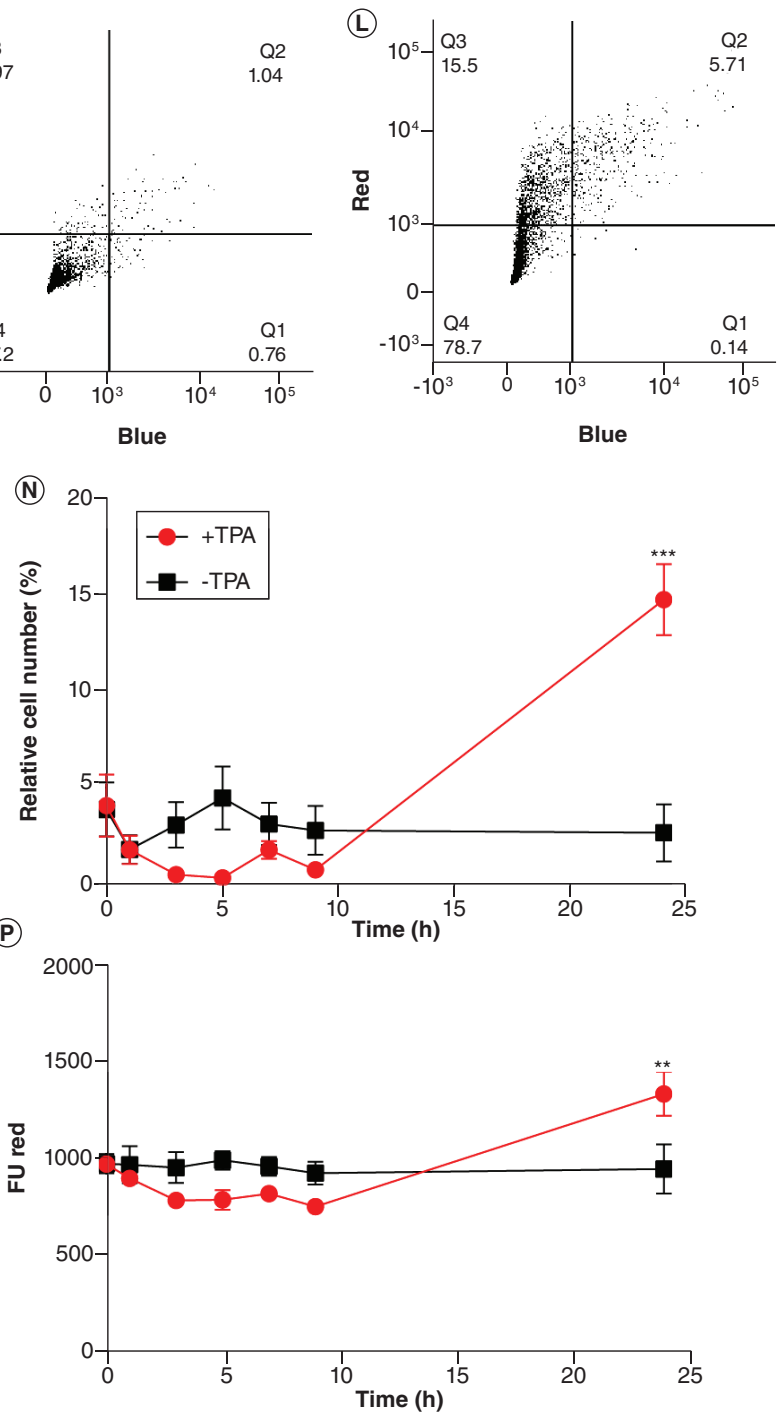

Figure 2. Phorbol 12-myristate 13-acetate-induced fluorescent timer expression and a time-dependent spectral shift (cont.). (J) The number of cells positive for red fluorescence was significantly increased at $24 \mathrm{~h}$ compared with the group without TPA stimulation. Representative FACS sorting images of cells (K) without TPA and (L) with TPA stimulation $24 \mathrm{~h}$ post-induction. (M) Relative cell number of blue cells to total cell number of cells was significantly upregulated between 3 and $7 \mathrm{~h}$ post-induction. $(\mathrm{N})$ Relative cell number of red cells to total number of cells was significantly upregulated $24 \mathrm{~h}$ post-induction. (0) Blue fluorescent intensity was significantly increased in the TPA-stimulated group $5 \mathrm{~h}$ post-induction compared with the unstimulated group. (P) Red fluorescent intensity was significantly upregulated at $24 \mathrm{~h}$ post-induction compared with the unstimulated group. Data was pooled from three individual experiments and represented as mean \pm SEM (two-way ANOVA with multiple comparison between +TPA and -TPA group for each time-point and Sidak's post-hoc correction).

${ }^{*} \mathrm{p}<0.05 ; * \star \mathrm{p}<0.01 ; * * * \mathrm{p}<0.001$.

FU: Fluorescence units; FACS: Fluorescence activated cell sorting; FSC: Forward scatter; SSC: Side scatter; TPA: Phorbol 12-myristate 13-acetate.

regression was performed. Heat maps were made using MeV software (MeV4.8.1., TM4).

\section{RESULTS \& DISCUSSION}

First, we constructed an expression plasmid with fast-maturing FT [9] under the control of a modified promoter of the activitydependent IEG Arc (E-SARE/ArcMin promoter) [14] (Figure 1A). Note that the AAV backbone can be used for viral preparation in future in vivo approaches.
FACS revealed a stimulus-dependent FT temporal spectral change

For a general overview on the functionality and temporal resolution of FT under the E-SARE/ArcMin promoter, we transfected cells with the plasmid and performed FACS analysis of single samples (Figure 1B). We induced IEG expression by stimulating with TPA. Negative control samples were measured in parallel, where transfected cells were not induced with TPA or untransfected cells were stimulated with TPA (Figure 2). Figure $2 \mathrm{~A}$ shows the gating strategy for single viable cells. Untransfected cells with TPA stimulation did not show a fluorescent signal (Figure 2B). The two transfected groups did not show any difference in fluorescent signal before induction with TPA (baseline), although a very low percentage of cells showed baseline activity (Figure 2C). $1 \mathrm{~h}$ after TPA stimulation, the number of cells with a positive fluorescent signal did not 


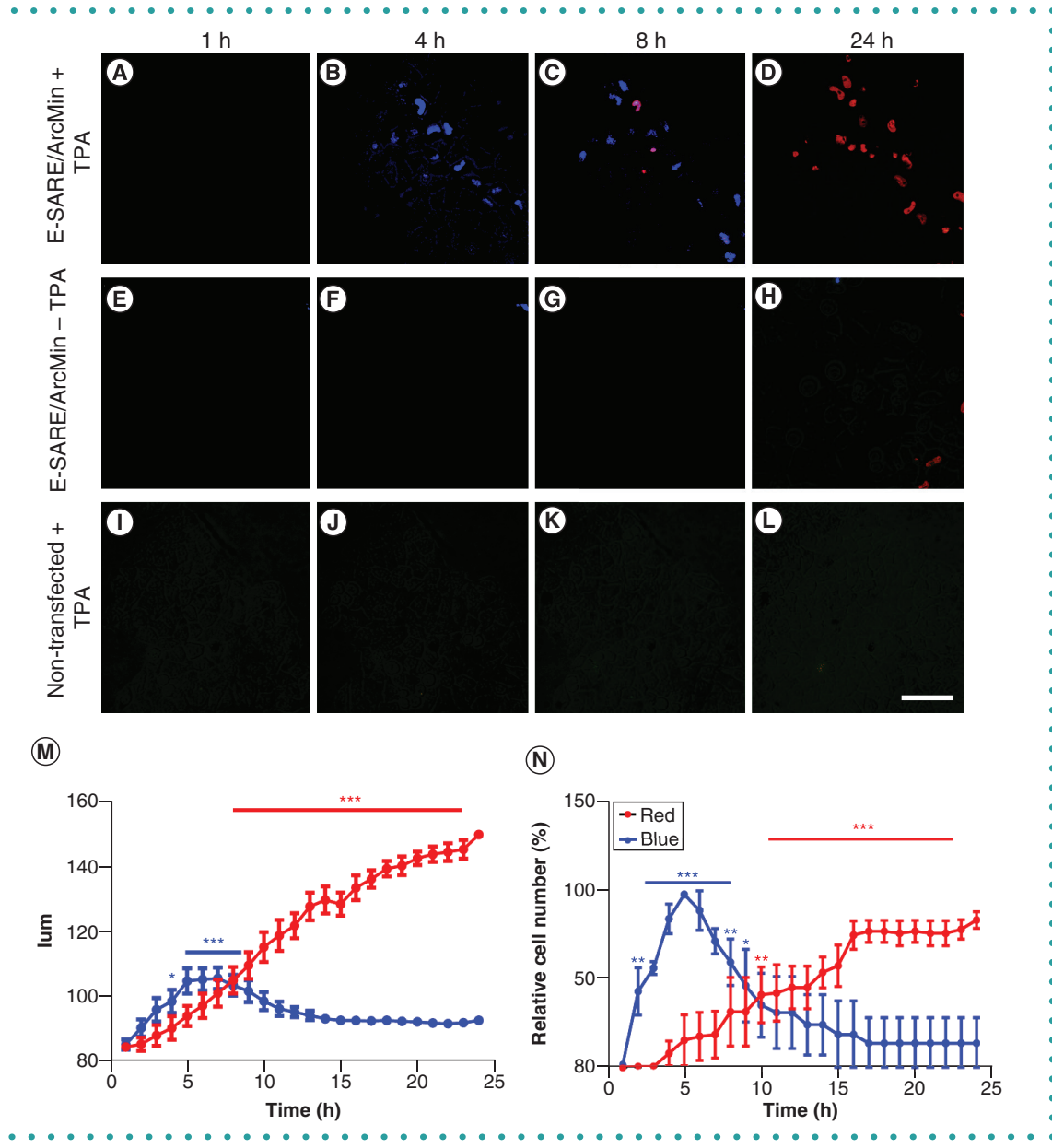

Figure 3. Live cell imaging enables longitudinal tracking of single cells over time. (A-D) Representative pictures of cells transfected with the FT construct and activated with TPA. (A) Cells did not show any fluorescence after $1 \mathrm{~h}$. (B) After $4 \mathrm{~h}$, cells in (A) clearly expressed blue fluorescence. (C) After $8 \mathrm{~h}$, the color had partially turned into a red fluorescence, which was (D) complete after $24 \mathrm{~h}$. $(\mathrm{E}-\mathrm{H})$ Cells transfected with the timer construct but without TPA stimulation only showed sporadic and weak blue and red signal. (I-L) Untransfected cells with TPA stimulation do not show any fluorescent signal. (M) Fluorescent intensity of single cells $(n=10)$ tracked over time shows a significant increase of blue fluorescence between 5 and $9 \mathrm{~h}$ post-induction compared with the first measurement at $t=1$. The red fluorescence shows a significant increase compared with $t=17 \mathrm{~h}$ postinduction until the end of measurement ( $24 \mathrm{~h}$ post-induction). $(\mathrm{N})$ The relative cell number positive for blue was significantly increased compared with $\mathrm{t}=1$ between 2 and $10 \mathrm{~h}$ post-induction. Red-positive cell number significantly increased from $10 \mathrm{~h}$ post-induction to the end of measurement $(n=3)$. Data are represented as mean \pm SEM. Scale bar corresponds to $20 \mu \mathrm{m}$. Two-way ANOVA with multiple comparisons between each time-point and $\mathrm{t}=1$ with Sidak's post-hoc correction.

${ }^{*} \mathrm{p}<0.05 ; * \star \mathrm{p}<0.01 ; * \star * \mathrm{p}<0.001$.

FT: fluorescent timer; TPA: Phorbol 12-myristate 13-acetate.

$\checkmark$ change. However, after $3 \mathrm{~h}$, the number of cells positive for blue fluorescence increased drastically compared with the number of positive cells before induction (T0), whereas no change was observed in unstimulated cells. The blue fluorescent signal remained constant for $2 \mathrm{~h}$, before it started to decrease (Figure 2D). In addition, the fraction of cells positive for blue fluorescence from the total cell number significantly increased compared with unstimulated samples and dropped after $9 \mathrm{~h}$ post-induction (Figure 2M). Figure 2E \& F show a representative sample $5 \mathrm{~h}$ post-induction. No change in fluorescence was visible in the unstimulated group (Figure 2E), whereas the stimulated group exhibited a drastic shift toward blue fluorescence (Figure 2F). $7 \mathrm{~h}$ and $9 \mathrm{~h}$ post TPA stimulation showed a significant increase in the number of cells positive for both blue and red fluorescence (Figure 2G). Consistent with these results, FACS at $9 \mathrm{~h}$ from unstim- ulated cells (Figure $2 \mathrm{H}$ ) and stimulated cells (Figure 2I) indicated a shift toward the double-positive quadrant only after TPA.

At $24 \mathrm{~h}$, we observed no cells positive for the blue signal but found a significant increase in the number of red fluorescent cells. Calculating the relative increase of the number of cells positive for red fluorescence compared with the number of positive cells before induction (T0), we found a significant increase in red fluorescing cells at $24 \mathrm{~h}$ post-induction, whereas no change was observed in unstimulated cells (Figure 2J). We observed a similar pattern when calculating the fraction of red fluorescing cells from the total number of cells. We also found a significant increase in red fluorescing cells at $24 \mathrm{~h}$ post-induction compared with unstimulated cells (Figure 2N). A representative FACS plot at $24 \mathrm{~h}$ post-induction time point is depicted in Figure 2K \& L. We did not find any change to baseline in the unstimulated sample (Figure 2K) but did observe a clear shift toward the red fluorescence in the stimulated sample (Figure $2 \mathrm{~L}$ ). In addition, we quantified blue and red fluorescence intensity of cells with FACS. Blue fluorescence slightly increased in treated and untreated cells $3 \mathrm{~h}$ post-induction. After $5 \mathrm{~h}$ post-induction, the treated cells showed a significant increase compared with unstimulated cells and a decrease at around $9-10 \mathrm{~h}$ post-induction (Figure 20 ). In contrast, the red signal drastically increased at $24 \mathrm{~h}$ post-induction (Figure 2P). Note that the weak increase of blue signal in the untreated cells most likely arose through the handling process of the cells before measurement (medium change, dislodging, etc.). We suggest that the slight drop in red fluorescence below baseline until $9 \mathrm{~h}$ postinduction also arose through the increased abundance of newly synthesized FT, which emitted a blue fluorescence and therefore overlaid the background red signal. As we did not investigate the protein or transcript abundancy of the FT in our study, all assumptions on protein abundancy are based on the fluorescent signal. However, Kawashima et al. performed those analyses in detail when they first described this construct [14].

Taken together, the FACS analyses revealed a stimulus-dependent FT temporal spectral change, which recorded a spectral time stamp of gene expression history. 


\section{All Synthetic FBS Replacement}

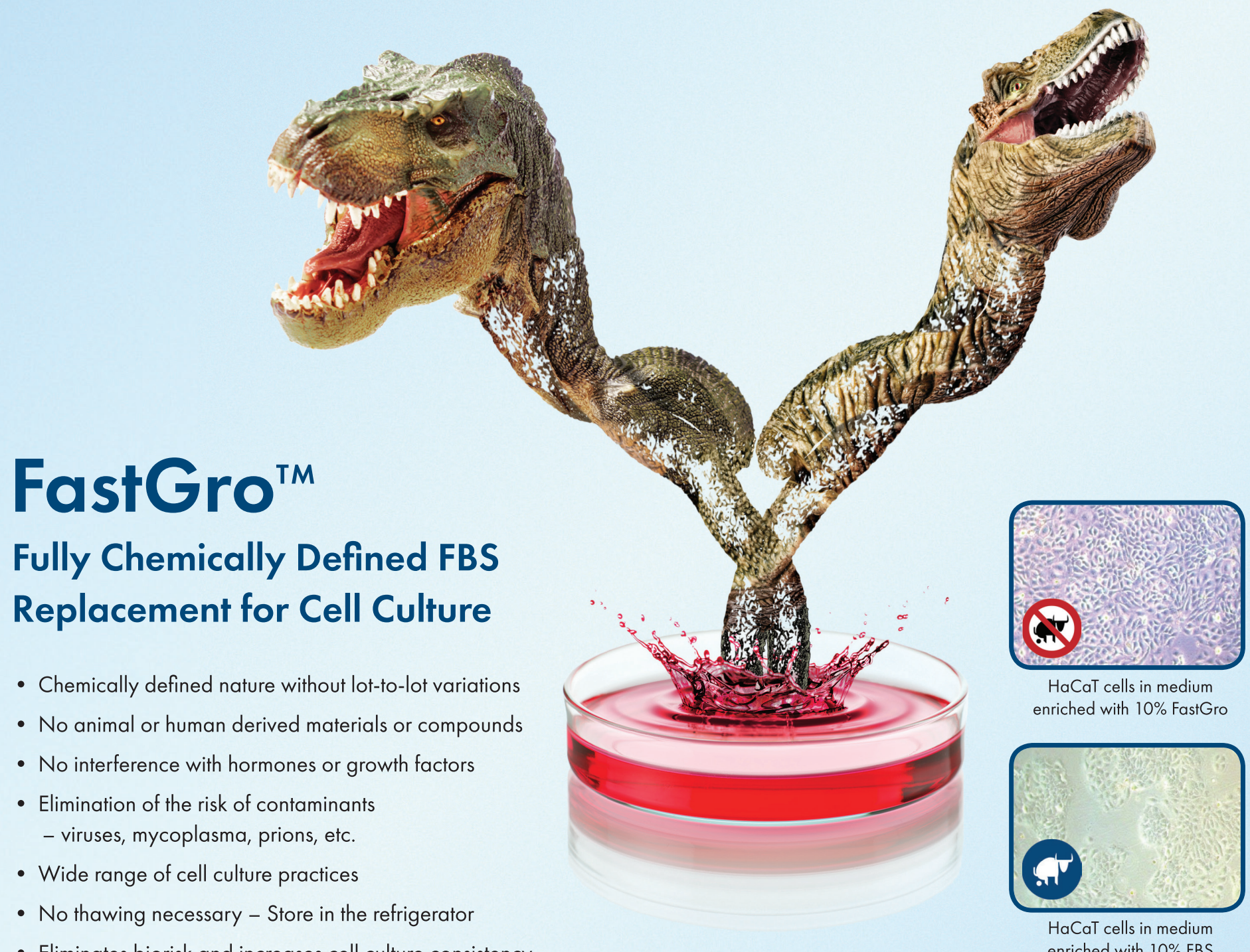

- Eliminates biorisk and increases cell culture consistency enriched with $10 \%$ FBS

Outrgrow your wildest cell growth No bull inside, all you need is FastGro

\section{LEARN MORE}

www.mpbio.com/fastgro 
(A)

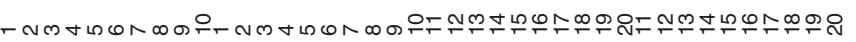

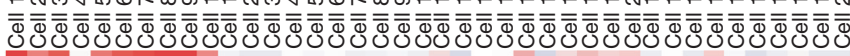

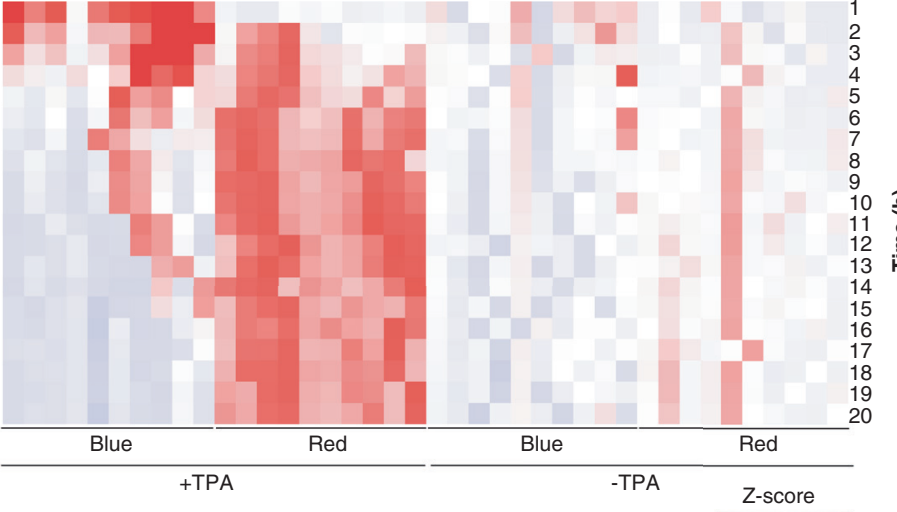

(C)

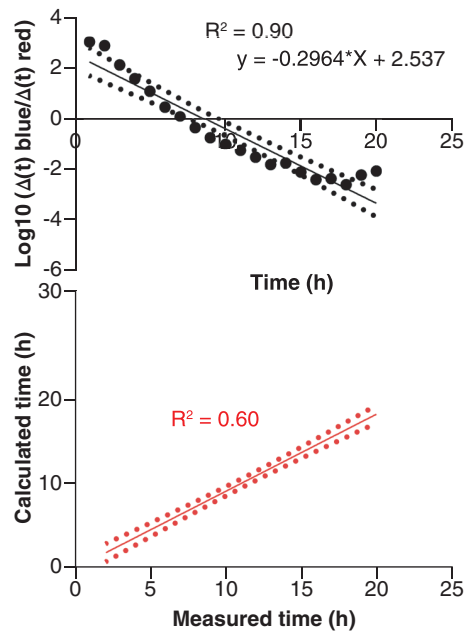

(F)
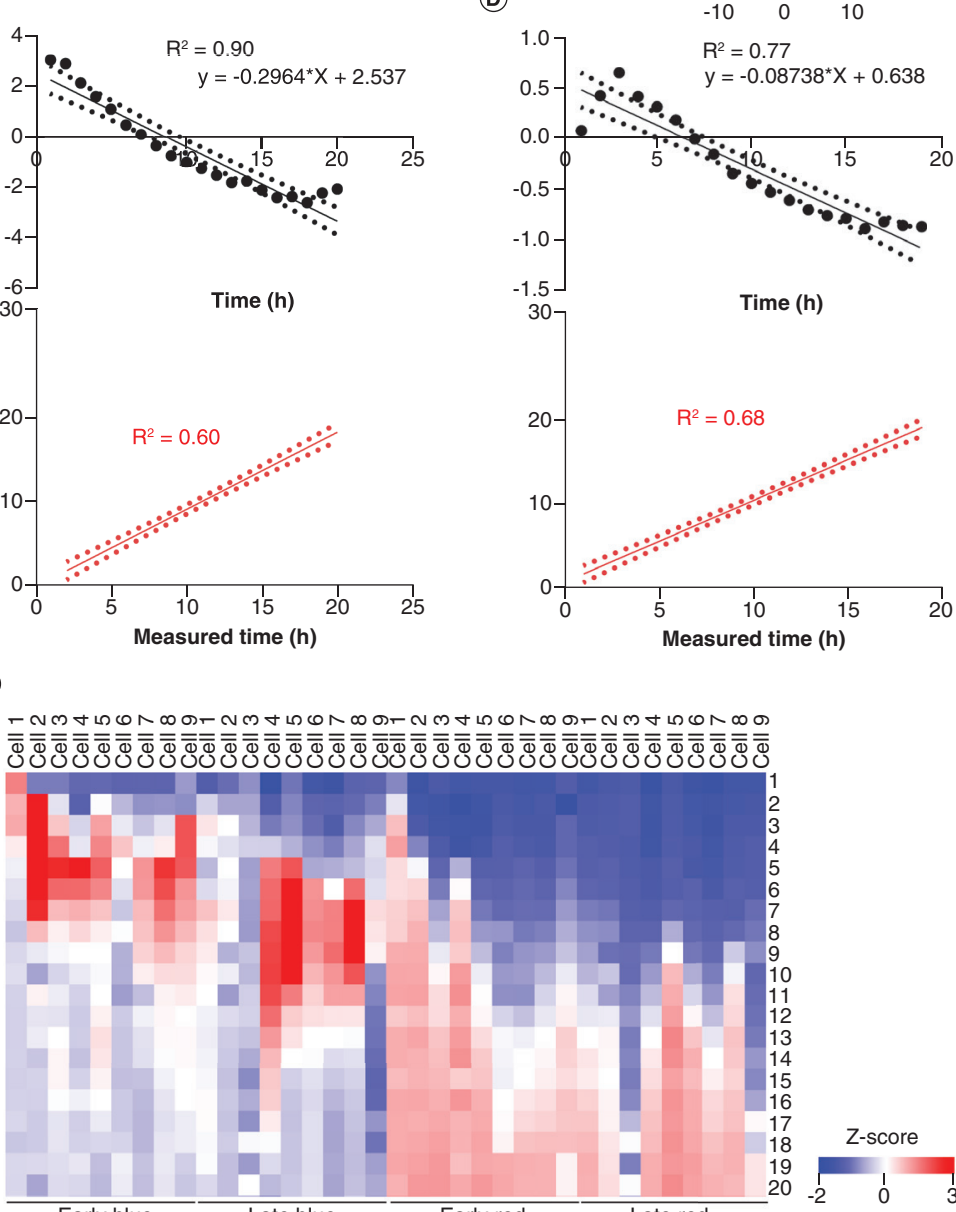

Z-score

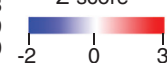

(B)
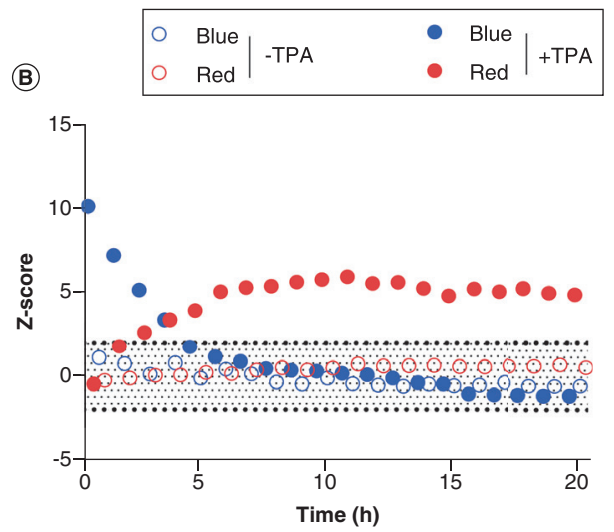

(E)

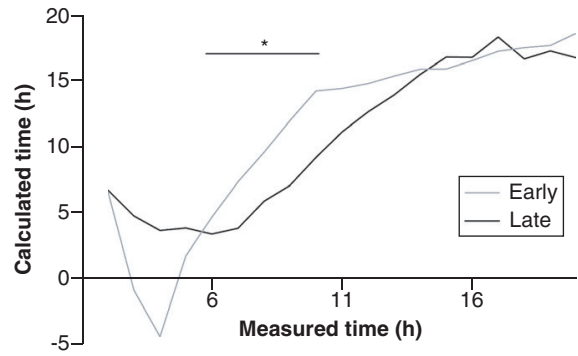

(G)

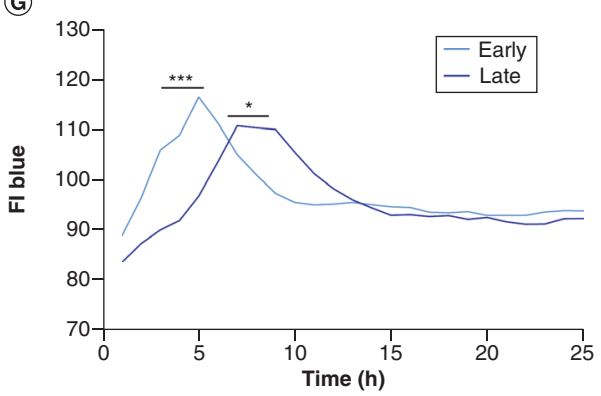

(H)
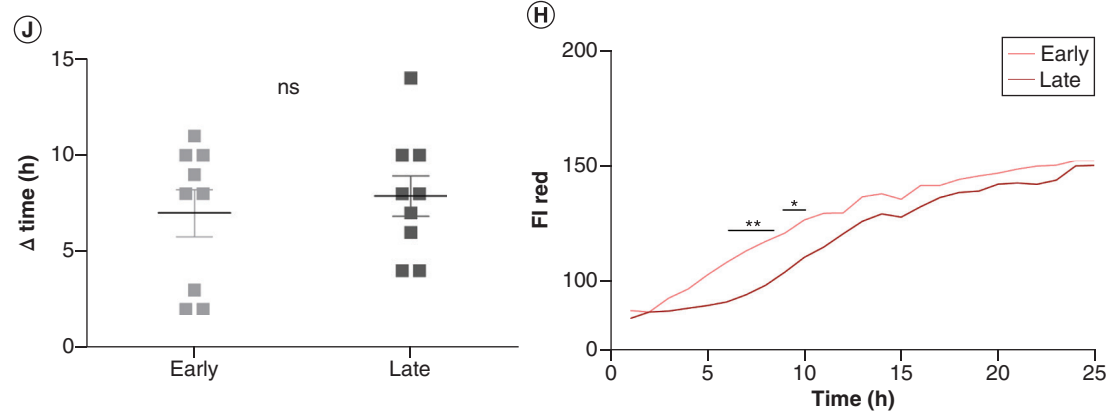
Figure 4. (See facing page) Post-hoc extrapolation of gene expression history. (A) Heat map of z-scores of fluorescence intensity of induced ( $\mathrm{n}=10$ ) and noninduced $(n=10)$ cells. (B) Noninduced cells show z-scores within a \pm 2 range at all measured time points, whereas induced cells clearly exceed this limit, enabling a mathematical differentiation of these two populations. (C) Top: Linear regression with a $95 \% \mathrm{Cl}$ of $\log _{10}(\Delta(\mathrm{t}) \mathrm{blue} / \Delta(\mathrm{t}) \mathrm{red})$ transformed fluorescent data from the mean fluorescence for blue and red of five single cells plotted over time with $R^{2}=0.90$. Bottom: Linear regression with a $95 \% \mathrm{Cl}$ of five cells from the same experiment not used for the linear regression fitting, $R^{2}=0.60$. Plot shows the time passed between induction and measurement (x-axis), and the time between induction and measurement as calculated by the formula indicated in Top ( $y$-axis). (D) Repeat of (C) with a bigger dataset from an independent experiment. Top: Linear regression with a $95 \% \mathrm{Cl}$ of nine single cells with $\mathrm{R}^{2}=0.77$. Bottom: Linear regression with a $95 \% \mathrm{Cl}$ of nine cells from the same experiment not used for the linear regression equation, $R^{2}=0.68$. (E) Calculated time post-induction from a single snapshot of a cell in time revealed early and late responders to stimulation $(n=18)$. (F) Heat map of $z$-scores of fluorescent intensities of cells split into early and late responders. (G) Post-hoc analysis of measured fluorescent intensity revealed a significant difference in response rates and induction of blue fluorescence, $(\mathrm{H})$ followed by a significantly different onset of the red signal $(\mathrm{n}=9$ per group). (I) No significant difference was detected in the duration of the blue fluorescent signal between early and late responders $(n=9 ; p=0.2)$. (J) The time from the first blue signal to the first red signal $(\Delta \operatorname{Time}(h))$ was not significantly different between early and late responders $(n=9 ; p=0.5)$. Data shown as mean \pm SEM. A two-tailed unpaired $t$-test revealed no significant difference $(p \geq 0.05)$ for any of the two tests. TPA: Phorbol 12-myristate 13-acetate.

\section{- Life-cell imaging allowed for longitudinal tracking of single cells} We then evaluated if our method can longitudinally track single cells. Thus, we incubated transfected cells on live-cell imaging microwell dishes, together with an untransfected control group. We stimulated one half of the transfected cells and the untransfected cells with TPA and imaged them for $24 \mathrm{~h}$ (Figure 1C \& Figure 3), while we imaged the other half of transfected cells without any TPA-induced stimulation. Individual cells were visually registered by their position in the image frames at different time points.
After $1 \mathrm{~h}$, we did not observe signal in any of the three groups (Figure 3A, E \& I). However, we did observe expression of FT $4 \mathrm{~h}$ postinduction in transfected cells stimulated with TPA, as indicated by blue fluorescently labeled cells (Figure 3B). Transfected cells without TPA stimulation showed very few positive cells (Figure $3 F$ ), and untransfected cells treated with TPA did not show any fluorescent signal $4 \mathrm{~h}$ post-induction (Figure $3 \mathrm{~J}$ ). $8 \mathrm{~h}$ after TPA stimulation, transfected cells showed a progressive color switch with some cells beginning to turn from blue to red (Figure 3C), whereas both control groups did not show any fluorescently labeled cells (Figure $3 \mathrm{G} \& \mathrm{~K}$ ). After $24 \mathrm{~h}$, all activated cells, indicated by blue fluorescence, had changed color, indicated by a pure red fluorescing signal (Figure 3D). In transfected cells without IEG induction by TPA, we observed only sparse red cells (Figure $3 \mathrm{H}$ ). We also observed no positive signal in untransfected cells (Figure $3 \mathrm{~L}$ ). The temporal progression of the color shift from blue to red is illustrated in a video of E-SARE/ArcMin-FT transfected cells induced with TPA imaged over $24 \mathrm{~h}$ (Supplementary information video 1). Cells without TPA induction only show

\section{Pipetting is FASTER with alf-O'}

\author{
The ONLY way \\ to accurately Repeat Pipette \\ using Serological Pipets!
}

- Faster and easier multidispensing with NO NEED to watch the lines.

- Repeatable accuracy* with the press of one button!

- Plus aspirate and dispense as you're used to.

- Use any size or brand of serological pipets.

- It's a 2 -in-1, regular \& repeating, pipet controller!

Ideal for cell culture, dispensing media, filling plates, tubes, cryovials, etc.

"This product saves us a great deal of time when performing large aliquotting jobs and does it more accurately than the average bench tech." - For more reviews see www.selectscience.net

${ }^{*}$ get $2 \%$ accuracy and $2 \% \mathrm{CV}$ using Wobble-not ${ }^{\mathrm{TM}}$ serological pipets. See www.vistalab.com/ali-q-pipet-controller for more info and specs.
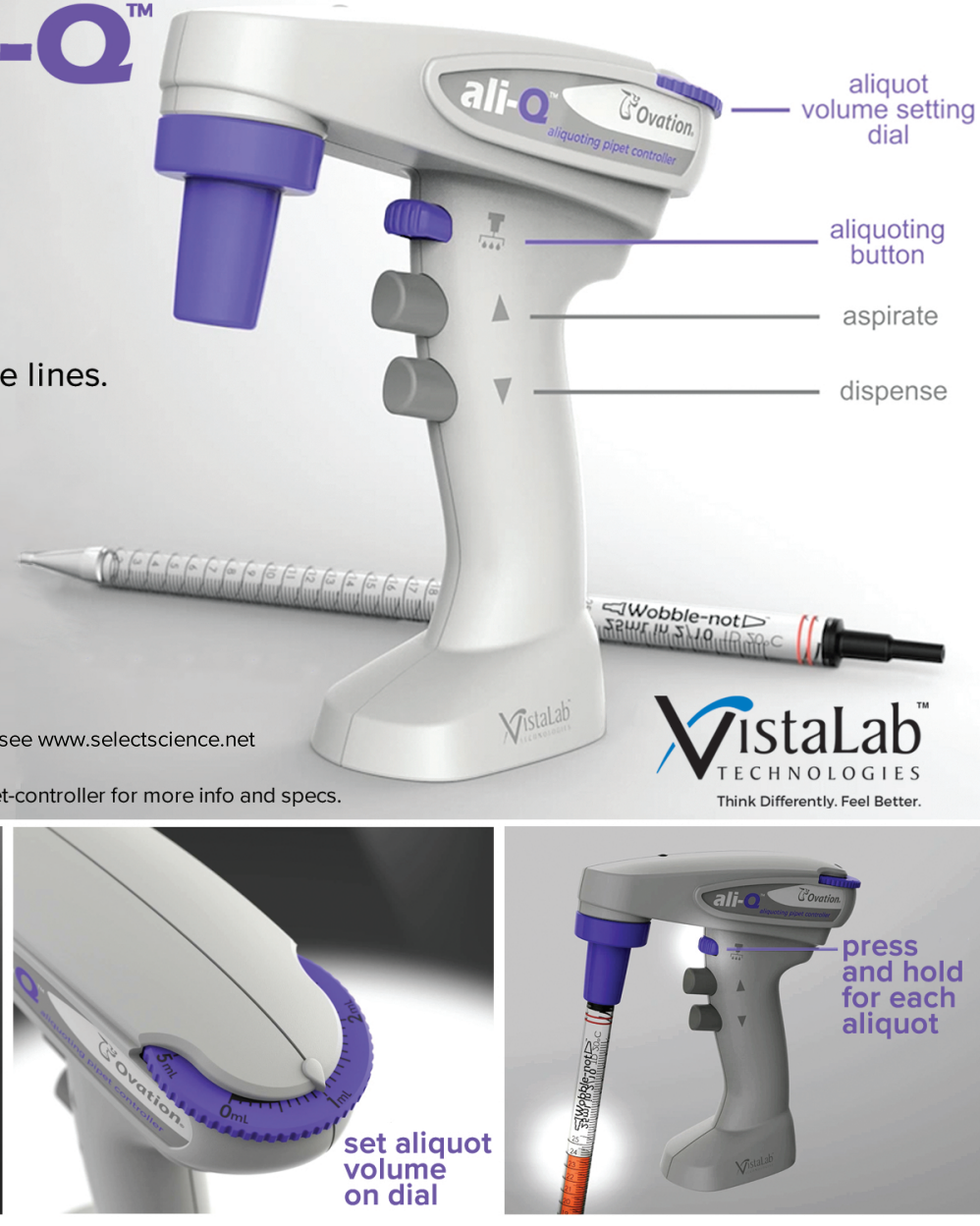
- weak background fluorescence (Supplementary information video 2).

We also quantified the fluorescent signal change of single transfected and stimulated cells from the first sign of FT expression (weak blue fluorescence) to a steady plateau of red fluorescence (Figure 3M). The blue fluorescence increased steadily within the first $3 \mathrm{~h}$ from an average fluorescent signal of 93 lum, after the first detected blue fluorescence in a cell to an average of 105 lum, $3 \mathrm{~h}$ after first detection. The signal intensity plateaued at this level for another $3 \mathrm{~h}$ before it began decreasing to a baseline level of approximately 90 lum. At the same time, the red fluorescence increased progressively from 85 lum at $1 \mathrm{~h}$ to about 140 lum, where it plateaued from $16 \mathrm{~h}$ to $24 \mathrm{~h}$ after the first detection of blue fluorescence. We then quantified the relative cell number positive for blue and red fluorescence. We calculated the relative cell number change compared with the number of positive cells $1 \mathrm{~h}$ after TPA stimulation. This analysis revealed a significant increase of blue fluorescent cells $2 \mathrm{~h}$ post TPA stimulation compared with the initial values at the first time point. The signal steadily increased until $5 \mathrm{~h}$ post-induction and then returned to baseline fluorescence $10 \mathrm{~h}$ postinduction. Yet, we found no cells positive for red fluorescence in the first $3 \mathrm{~h}$ after which the signal steadily increased until about $7 \mathrm{~h}$ post-induction, when red fluorescence drastically increased compared with $1 \mathrm{~h}$ post-induction. After $16 \mathrm{~h}$, the number of cells reached its peak and stayed constant until the end of the measurements (Figure $3 \mathrm{~N}$ ). We therefore validated our promoter::FT fusion in longitudinal tracking of single cells experiments using live cell imaging, allowing spatio-temporal resolution of gene expression in vivo on a single cell basis. The potential blue-to-red photoconversion [8] was negligible in our imaging conditions, as the color conversion kinetics overlapped with our results from FACS analysis. Furthermore, we demonstrated that the color conversion kinetics were quite stable under constant conditions. The chromatic change we observed here differs from Subach et al. reported in their original paper, in line with their notion that the kinetics were highly dependent on temperature and the cell type in which the protein is expressed [9].
Post-hoc reconstruction of cellular activity profiles

We then applied a mathematical approach to differentiate induced and noninduced cells. Thus, we calculated the $z$-score of the blue and red fluorescence and found a clear differentiation in the signal intensity between the two groups (Figure 4A). Plotting these values enabled us to delineate a cut-off range of a z-score of \pm 2 , which clearly differentiated induced and noninduced cells (Figure 4B). Further, we exploited steady kinetics of the color shift and established a model to extrapolate the time point of IEG activation in single cells (Figure $4 C \& D$ ). Establishing a model on a training set reliably approximated the time that passed between the induction of a cellular response and a single measurement during live cell imaging $\left(R^{2}=0.9\right.$; Figure $4 C$, top). We calculated the time of induction of cells in a test set (from the same experiment) not used to establish the model and could predict the correct induction time in $60 \%$ of the timepoints of all cells $\left(R^{2}=0.60\right.$; Figure $4 C$, bottom). Furthermore, we successfully repeated this workflow in an independent experiment on a bigger dataset (Figure 4D). Although it is crucial to establish the exact kinetics in each independent experiment (due to the sensitivity of the FT to external factors, such as temperature; see regression used in Figure 4D), the model itself allows for extrapolating the time of induction of randomly chosen single cells from a snapshot in time.

Importantly, this model uncovered two populations of cells in this data, which showed a different response kinetic to the stimulus: slow and fast responders (Figure 4E). Reinspection of the live-cell imaging data indeed revealed different response rates to the initial stimulus. Some cells were bright blue after $4 \mathrm{~h}$, whereas some other cells were only blue after $8 \mathrm{~h}$, when the first blue cells had already turned red, indicating two populations with different stimulus response latencies (Figure 4F). Many cells showed a strong, prominent peak very early after induction $(5 \mathrm{~h})$, whereas the slow responders needed longer (7-10 h) to induce FT expression (Figure 4G). Among the different response rates of the two populations, the duration of the blue signal was not significantly different in the two populations (Figure 4I).
The FT also required the same amount of time for the conversion from blue to red with a $\Delta$ Time(h) of about $7.5 \mathrm{~h}$ in both populations (Figure 4J). Therefore, the first cells showing a blue signal were also the first ones emitting red fluorescence (after about 7-10 h) and the cells emitting blue fluorescence later where the last ones to emit a red signal ( $15 \mathrm{~h}$ post-induction), validating the steady kinetics of the FT (Figure $4 \mathrm{H}$ ). As we did not synchronize cells, the different response rates most likely indicated different stages of the cell cycle of each individual cell when IEG promoter activity was high and FT expression was induced.

Hence, our promoter::FT fusion helped establish a mathematical approach to refer the time of the cell stimulation from a single snapshot of individual cells and differentiate it from uninduced cells (Supplementary Figure S1A). This revealed a detailed dissection of gene expression on a single-cell basis, which could then be used for further analysis such as singlecell sequencing. This detailed temporal resolution of different cell populations within a group is not possible with classical FP, as this method only indicates the expression of the gene of interest but not the time of its initiation $[5,9,12]$. Activity-dependent FT expression also provides a very convenient method to determine the time different cells require to respond to one stimulus without any further hands-on time for the experimenter. In addition, the red fluorescence signal of the FT protein stayed high throughout our measurement period, so we could track every activated cell to uncover the gene expression history of each individual unit.

FT proteins emerged as a promising tool in life science research [15]; for example, to monitor protein dynamics $[5,13]$. We expanded its application to meet the growing interest in FT proteins [16-18] by enabling longitudinal tracking of gene expression in single cells. We expect our promoter::FT fusion to add new dimensions to any experiment where tracking the temporal pattern of gene expression in complex mixtures of cells from culture, tissues and living organisms is of importance (Supplementary Figure S1B). This scenario may apply to ex vivo characterization from stimulus responders in both the immune system and the brain, which could be directly monitored by the IEG 
promoter::FT fusion presented here. In the latter, this methodology should identify and sort cells from a single time point to reconstruct neuronal ensembles responding to temporally separated stimuli [19], similar to c-Fos catfish [20]. Our methodology has the advantage of being compatible with and integrated with follow-up live cell analysis workflows for further characterization (e.g., proteomic or transcriptional singlecell analyses). Importantly, it also enables retracing complex temporal changes in assembling ensembles at different time points.

\section{FUTURE PERSPECTIVE}

In conclusion, we present an approach to enable monitoring gene expression in vivo on a single cell basis over time. The kinetics of the spectral shift allow for post-hoc reconstruction of stimulus and gene expression history from a single snapshot in time. This method can integrate into follow-up live cell analysis workflows for further characterization (e.g., proteomic or transcriptional single-cell analyses), which is relevant for a broad research community.

\section{SUPPLEMENTARY DATA}

To view the supplementary data that accompany this paper please visit the journal website at: www.future-science. com/doi/suppl/10.2144/btn-2019-0050

\section{AUTHOR CONTRIBUTIONS}

AT performed cell culture experiments and imaging, FACS as well as analysis. BW and AT cloned the plasmid. AT prepared the figures and together with $\mathrm{NK}$ and $\mathrm{WH}$ prepared the manuscript. NK and WH supervised the project and contributed equally.

\section{ACKNOWLEDGMENTS}

The authors would like to thank D Kargl for the methodological help and the Biooptics department of the core facility of the Institute of Molecular Pathology, for support with microscopy and FACS. We thank Life Science Editors for editorial assistance.

\section{FINANCIAL \& COMPETING INTERESTS DISCLOSURE}

WH was supported by a grant from the European Community's Seventh Framework Programme (FP/2007-2013)/ ERC grant agreement no. 311701 , the
Research Institute of Molecular Pathology (IMP), Boehringer Ingelheim and the Austrian Research Promotion Agency (FFG). NK was supported by long-term postdoctoral fellowships from Fyssen Foundation, EMBO (grant no. 1214-2012) and Marie Curie Actions (grant no. 331015). The authors have no other relevant affiliations or financial involvement with any organization or entity with a financial interest in or financial conflict with the subject matter or materials discussed in the manuscript apart from those disclosed.

No writing assistance was utilized in the production of this manuscript.

\section{OPEN ACCESS}

This work is licensed under the Creative Commons Attribution 4.0 License. To view a copy of this license, visit http://creativecommons.org/licenses/by/4.0/

\section{REFERENCES}

1. Shimomura O, Johnson FH, Saiga Y. Extraction, purification and properties of aequorin, a bioluminescent protein from the luminous hydromedusan, Aequorea. Cell Comp. Physiol. 59, 223-239 (1962).

2. Chalfie M, Tu Y, Euskirchen G, Ward WW, Prasher DC. Green fluorescent protein as a marker for gene expression. Science 263, 802-805 (1994).

3. Prasher DC, Eckenrode VK, Ward WW, Prendergast FG, Cormier MJ. Primary structure of the Aequorea victoria green-fluorescent protein. Gene 111, 229-233 (1992).

4. Eden E, Geva-Zatorsky N, Issaeva I et al. Proteome half-life dynamics in living human cells. Science 331 764-768 (2011)

5. Knop M, Edgar BA. Tracking protein turnover and degradation by microscopy: photo-switchable versus time-encoded fluorescent proteins. Open Biol. 4(4), 140002 (2014).

6. Lippincott-Schwartz J, Patterson GH. Fluorescent proteins for photoactivation experiments. Methods Cell Biol. 85, 45-61 (2008)
7. Subach FV, Zhang L, Gadella TWJ, Gurskaya NG, Lukyanov KA, Verkhusha VV. Red fluorescent protein with reversibly photoswitchable absorbance for photochromic FRET. Chem. Biol. 17, 745-755 (2010).

8. Wu B, Piatkevich KD, Lionnet T, Singer RH, Verkhusha VV. Modern fluorescent proteins and imaging technologies to study gene expression, nuclear localization, and dynamics. Curr. Opin. Cell Biol. 23, 310-317 (2011).

9. Subach FV, Subach OM, Gundorov IS et al. Monomeric fluorescent timers that change color from blue to red report on cellular trafficking. Nat. Chem. Biol. 5, 118-126 (2009).

10. Duncan RR, Greaves J, Wiegand UK et al. Functional and spatial segregation of secretory vesicle pools according to vesicle age. Nature 422, 176-180 (2003).

11. Mirabella R, Franken C, van der Krogt GNM, Bisseling T, Geurts R. Use of the fluorescent timer DsRED-E5 as reporter to monitor dynamics of gene activity in plants. Plant Physiol. 135, 1879-1887 (2004).

12. Terskikh A, Fradkov A, Ermakova G et al. "Fluorescent timer": protein that changes color with time. Science 290, 1585-1588 (2000).

13. Khmelinskii A, Keller PJ, Bartosik A et al. Tandem fluorescent protein timers for in vivo analysis of protein dynamics. Nat. Biotechnol. 30, 708-714 (2012).

14. Kawashima T, Kitamura K, Suzuki K et al. Functional labeling of neurons and their projections using the synthetic activity-dependent promoter E-SARE. Nat. Methods 10, 889-895 (2013).

15. Gagescu R. Fluorescent timer. Nat. Rev. Mol. Cell Biol. 2, 9 (2001).

16. Bending D, Martín PP, Paduraru A et al. A timer for analyzing temporally dynamic changes in transcription during differentiation in vivo. J. Cell Biol. 217, 2931-2950 (2018)

17. Ohara S, Sota Y, Sato S, Tsutsui K-I, Iijima T. Increased transgene expression level of rabies virus vector for transsynaptic tracing. PLoS One 12(7), e0180960 (2017)

18. Xia A, Han J, Jin Z, Ni L, Yang S, Jin F. Dual-color fluorescent timer enables detection of growth-arrested pathogenic bacterium. ACS Infect. Dis. 4, 1666-1670 (2018)

19. Josselyn SA, Frankland PW. Memory allocation: mechanisms and function. Annu. Rev. Neurosci. 41, 389-413 (2018).

20. Guzowski JF, McNaughton BL, Barnes CA, Worley PF. Imaging neural activity with temporal and cellular resolution using FISH. Curr. Opin. Neurobiol. 11, 579-584 (2001).

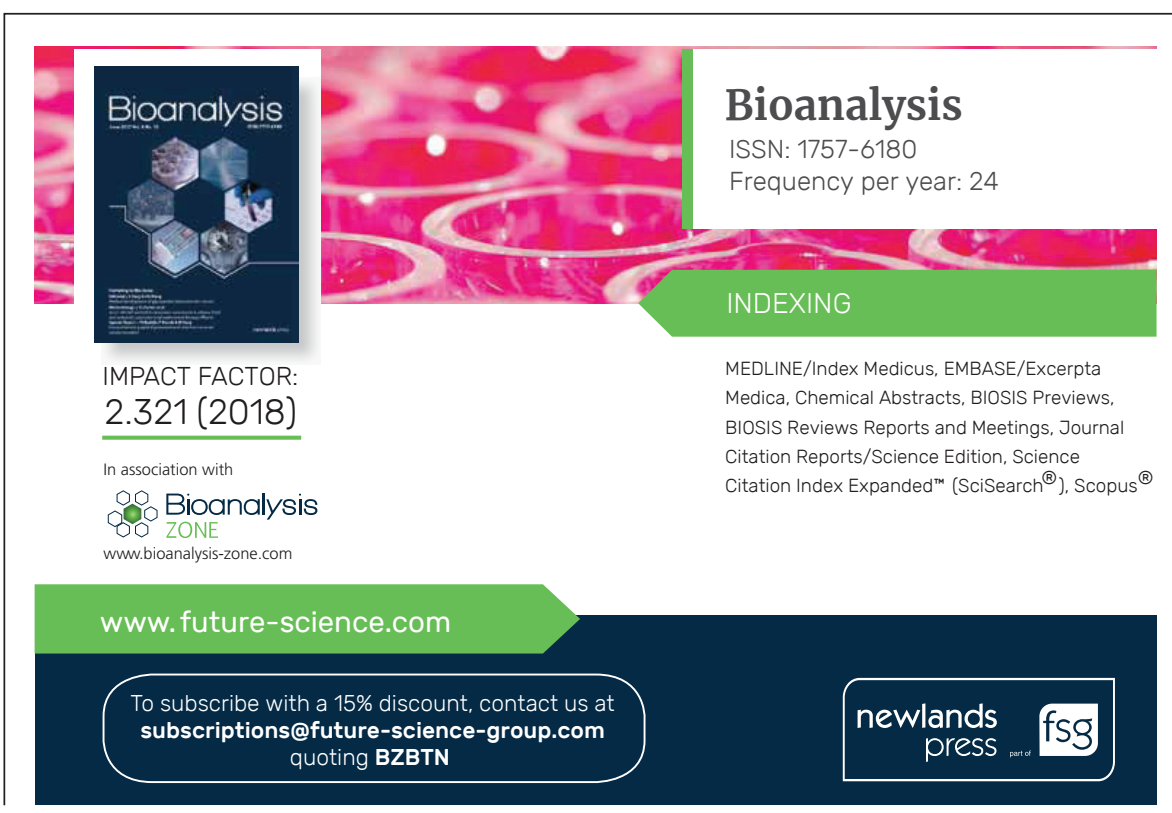

